\title{
Response to vitamin D replacement in overweight and normal weight children with vitamin D deficiency
}

\author{
In Hyuk Chung, MD', \\ Yu Sun Kang, MD', \\ Eun-Gyong Yoo, MD, PhD²
}

'Department of Pediatrics, National Health Corporation Ilsan Hospital, Goyang, Korea

2Department of Pediatrics, CHA Bundang Medical Center, CHA University School of Medicine, Seongnam, Korea
Purpose: It is well known that obesity is related to vitamin D deficiency (VDD). We investigated the response to vitamin $\mathrm{D}$ replacement in normal-weight and overweight children.

Methods: This was a prospective study including 62 Korean children with VDD. VDD was defined as a serum 25 -hydroxycholecalciferol $(25(\mathrm{OH}) \mathrm{D})$ concentration $<20 \mathrm{ng} /$ $\mathrm{mL}$. Overweight was defined as a body mass index $(\mathrm{BMI}) \geq$ the 85 th percentile $(n=21)$, and normal weight as a BMI between the 5 th and 84 th percentiles $(n=41)$. All participants received vitamin D3 supplementation (2,000 IU/day) for 8 weeks. The serum levels of $25(\mathrm{OH}) \mathrm{D}, \mathrm{PTH}$ and biochemical parameters were measured before and after treatment.

Results: The mean age was 10.0 1.4 years in normal-weight children and 10.0 2.1 years in overweight children ( $P=0.93)$. After 8 weeks of treatment, $61.9 \%$ of normalweight children and $47.6 \%$ of overweight children achieved vitamin $D$ sufficiency ( $P$ $=0.30$ ). The mean serum $25(\mathrm{OH}) \mathrm{D}$ levels after vitamin $\mathrm{D}$ replacement were $33.8 \pm 7.6$ $\mathrm{ng} / \mathrm{mL}$ and $30.3 \pm 6.6 \mathrm{ng} / \mathrm{mL}$ in normal-weight and overweight children, respectively $(P=0.10)$. The mean calcium/creatinine ratios after treatment were $0.09 \pm 0.07$ and $0.08 \pm 0.06$ in the normal-weight and overweight groups, respectively, and no hypercalciuria was found. In multiple regression analysis, the response to vitamin $D$ replacement was influenced by the BMI $(\beta=-1.0, P=0.03)$ and sex $(\beta=-4.0, P=0.04)$.

Conclusion: Eight weeks of vitamin D replacement $(2,000 \mathrm{IU} /$ day $)$ is sufficient to overcome vitamin $\mathrm{D}$ deficiency in normal-weight and overweight children without any complications.

Keywords: Vitamin D, Child, Supplement, Overweight, Obesity

\section{Introduction}

Vitamin D is a major component of calcium, phosphorus, and bone metabolism. vitamin D Received: 18 May, 2018

Revised: 25 July, 2018

Accepted: 21 August, 2018

Address for correspondence: Eun-Gyong Yoo, MD, PhD

Department of Pediatrics, CHA Bundang Medical Center, CHA University School of Medicine, 59 Yatap-ro, Bundang-gu, Seongnam 13496, Korea

Tel: +82-31-780-1959

Fax: +82-31-780-5239

E-mail: pedyoo@cha.ac.kr

http://orcid.org/0000-0002-6452-

$655 \mathrm{X}$ deficiency (VDD) causes inadequate calcium and phosphorus absorption in the intestine, thus increasing parathyroid hormone levels. ${ }^{1,2)}$

The risk factors for vitamin D deficiency are high latitudes, the winter season, and inadequate durations of sunlight exposure. The extent of skin pigmentation, aging and sunscreen use also influence the risk of vitamin D deficiency. ${ }^{2)}$

Many clinical and epidemiological studies have demonstrated that the obesity level, body mass index (BMI), waist circumference (WC), and visceral fat amount correlate negatively with serum vitamin D concentration, but the underlying mechanism is uncertain. ${ }^{3-5)}$

According to our previous study, the prevalence of VDD was $55.3 \%$ in normal-weight and $71.4 \%$ in overweight Korean children.

It has been suggested that 2 or 3 times greater vitamin D replacement is required to treat VDD in obese individuals than in normal-weight individuals, ${ }^{7}$ but little is known about the treatment response in overweight children. ${ }^{8)}$ 
This study was performed to investigate the response to vitamin D replacement in normal-weight and overweight children.

\section{Materials and methods}

\section{Participants}

This was a prospective study including 62 Korean children between 8 and 15 years of age. All participants visited CHA Bundang Medical Center for the evaluation of health and growth status. During the first visit, all participants were interviewed with a health questionnaire, and anthropometric measurements and blood sampling were performed. The exclusion criteria were (1) children with BMIs $<$ the $3 \mathrm{rd}$ percentile, (2) those with chronic and/or genetic diseases, (3) those who had received vitamin D supplementation before their first visit, (4) those with abnormal laboratory results (abnormal liver, kidney or thyroid function tests or hemoglobin levels $<11$ $\mathrm{g} / \mathrm{dL}$ ) and (5) those who displayed reduced compliance.

VDD was defined as a serum 25-hydroxycholecalciferol $(25(\mathrm{OH}) \mathrm{D})$ concentration $<20 \mathrm{ng} / \mathrm{mL}$, and vitamin D sufficiency as $\geq 30 \mathrm{ng} / \mathrm{mL}^{7}{ }^{7)}$ Based on the 2017 Korean standard growth curve, normal weight was defined as a BMI from the 3 rd to the 84 th percentile, and overweight as a BMI $\geq$ the 85 th percentile for age and sex. ${ }^{9)}$ At the first visit, blood was sampled before the replacement of vitamin D. After VDD was confirmed, 45 normal-weight and 23 overweight children were included. Informed consent was obtained from each participant and their parents. Due to reduced compliance, 4 of 45 normal-weight and 2 of 23 overweight children were excluded. This study was approved by the CHA Bundang Medical Center Institutional Review Board (approval number: BD 2013-126).

\section{Methods}

Vitamin D replacement was performed in winter, between December 2013 and February 2014, to minimize the influence of sunlight exposure. A bottle of vitamin D3 (10 mL, 1,000 IU per $0.0279 \mathrm{~mL}$ [=one drop]; Sunny D drops, FND Net Co., Seoul, Korea) was provided, and all participants received vitamin D3 supplementation (2,000 IU/day) for 8 weeks. ${ }^{10)}$ At a follow-up visit after vitamin $\mathrm{D}$ replacement, the remaining volume of vitamin D was checked to confirm the participants compliance (6 participants were excluded).

An electric scale (DB-1, CAS, Yangju, Korea) for weight and a stadiometer (Holtain Limited, Pembrokeshire, Britain) for height were used for the anthropometric measurements. WC was measured at the midpoint between the lower margin of the least palpable rib and the top of the iliac crest after exhalation. ${ }^{11)}$

Serum 25(OH)D was measured with a chemiluminescence immunoassay (LIAISON system, DiaSorin, Italy), while serum PTH was measured with an electrochemiluminescence immunoassay (Roche Diagnostics, Indianapolis, IN, USA), and serum calcium, ionized calcium, phosphorus, alkaline phosphatase, total cholesterol, triglycerides, high-density lipoprotein cholesterol and low-density lipoprotein cholesterol were measured spectrophotometrically (HITACHI Automatic Analyzer, Tokyo, Japan) before and after treatment. Urine was collected before and after vitamin D replacement for analysis of the urinary calcium/creatinine ratio.

\section{Statistical analysis}

Data were analyzed with IBM SPSS ver. 23.0 (IBM Co., Armonk, NY, USA). The BMI $z$-score was calculated by the LMS method, ${ }^{12)}$ and the body surface area (BSA) was calculated according to the Mosteller formula. ${ }^{13)}$ The mean values of the 2 groups were compared by Student $t$-test. A paired $t$-test was used to compare the mean values before and after treatment. Multiple regression analysis was used to identify factors affecting the increment of $25(\mathrm{OH}) \mathrm{D}(\Delta 25(\mathrm{OH}) \mathrm{D})$. A $P$-value $<0.05$ was considered significant.

\section{Results}

\section{Baseline Characteristics}

The mean age was $10.0 \pm 1.4$ years in the normal-weight group $(n=41)$ and $10.0 \pm 2.1$ years in the overweight group $(\mathrm{n}=21)(P=0.93)$. The height, weight, $\mathrm{WC}$, waist-to-height ratio (WHtR), BMI, BMI $z$-score, BSA and body fat (\%) values were significantly higher in the overweight group (Table 1 ).

\section{Laboratory and anthropometric results of participants before and after vitamin $\mathrm{D}$ replacement}

In the normal-weight group, after vitamin $\mathrm{D}$ replacement, the serum $25(\mathrm{OH}) \mathrm{D}$ concentration increased from $12.9 \pm 3.1$ to $33.8 \pm 7.6 \mathrm{ng} / \mathrm{mL}(P<0.05)$, and the calcium level also improved $(9.1 \pm 0.5$ to $9.5 \pm 0.3 \mathrm{mg} / \mathrm{dL}, P<0.05)$. In the overweight group,

Table 1. Anthropometric characteristics of participants

\begin{tabular}{lccr} 
Characteristic & $\begin{array}{c}\text { Normal weight group } \\
(\mathrm{n}=41)\end{array}$ & $\begin{array}{c}\text { Overweight group } \\
(\mathrm{n}=21)\end{array}$ & P-value \\
\hline Male sex & $19(46.3)$ & $7(33.3)$ & 0.33 \\
Age $(\mathrm{yr})$ & $10.0 \pm 1.4$ & $10.0 \pm 2.1$ & 0.93 \\
Height $(\mathrm{cm})$ & $137.3 \pm 9.1$ & $144.8 \pm 13.3$ & 0.03 \\
Weight $(\mathrm{kg})$ & $33.7 \pm 6.2$ & $50.1 \pm 16.3$ & $<0.01$ \\
WC $(\mathrm{cm})$ & $62.3 \pm 7.0$ & $77.0 \pm 11.0$ & $<0.01$ \\
WHtR & $0.42 \pm 0.13$ & $0.51 \pm 0.13$ & 0.01 \\
BMl $\left(\mathrm{kg} / \mathrm{m}^{2}\right)$ & $17.9 \pm 2.0$ & $23.3 \pm 3.6$ & $<0.01$ \\
BMl z-score & $0.04 \pm 0.76$ & $1.66 \pm 0.53$ & $<0.01$ \\
BSA $\left(\mathrm{m}^{2}\right)$ & $1.13 \pm 0.13$ & $1.41 \pm 0.29$ & $<0.01$ \\
Body fat (\%) & $22.5 \pm 6.3$ & $32.4 \pm 6.2$ & $<0.01$ \\
\hline Values are presen
\end{tabular}

Values are presented as number (\%) or mean \pm standard deviation. WC, waist circumference; WHtR, waist to height ratio; $\mathrm{BMI}$, body mass index; BSA, body surface area. 
Table 2. Laboratory and anthropometric results of participants before vs. after vitamin D replacement

\begin{tabular}{|c|c|c|c|c|}
\hline \multirow{2}{*}{ Variable } & \multicolumn{2}{|c|}{ Normal weight group } & \multicolumn{2}{|c|}{ Overweight group } \\
\hline & Before vitamin D replacement & After vitamin D replacement & Before vitamin D replacement & After vitamin D replacement \\
\hline $25(\mathrm{OH}) \mathrm{D}(\mathrm{ng} / \mathrm{mL})$ & $12.9 \pm 3.1$ & $33.8 \pm 7.6^{*}$ & $14.2 \pm 2.1$ & $30.3 \pm 6.6^{*}$ \\
\hline PTH $(p g / m L)$ & $32.3 \pm 9.7$ & $31.9 \pm 14.7$ & $39.5 \pm 18.0$ & $30.5 \pm 11.0$ \\
\hline Calcium (mg/dL) & $9.1 \pm 0.5$ & $9.5 \pm 0.3^{*}$ & $9.5 \pm 0.3$ & $9.3 \pm 0.3$ \\
\hline Phosphorus (mg/dL) & $5.0 \pm 0.6$ & $4.9 \pm 0.4$ & $5.1 \pm 0.5$ & $4.7 \pm 0.3^{*}$ \\
\hline $\mathrm{ALP}(I U / L)$ & $309.8 \pm 83.1$ & $314.1 \pm 97.1$ & $320.0 \pm 116.8$ & $276.8 \pm 64.4$ \\
\hline Calcium/creatinine ratio ${ }^{\dagger}$ & $0.06 \pm 0.05$ & $0.09 \pm 0.07$ & $0.07 \pm 0.05$ & $0.08 \pm 0.06$ \\
\hline Total cholesterol (mg/dL) & $168.7 \pm 22.2$ & $158.0 \pm 19.2^{*}$ & $167.1 \pm 29.1$ & $168.4 \pm 23.9$ \\
\hline Triglyceride (mg/dL) & $79.6 \pm 32.7$ & $65.7 \pm 27.4$ & $74.1 \pm 33.7$ & $68.0 \pm 36.0$ \\
\hline $\mathrm{HDL}-\mathrm{C}(\mathrm{mg} / \mathrm{dL})$ & $57.4 \pm 10.5$ & $56.9 \pm 10.0$ & $57.2 \pm 10.8$ & $53.5 \pm 11.9$ \\
\hline $\mathrm{LDL}-\mathrm{C}(\mathrm{mg} / \mathrm{dL})$ & $97.1 \pm 22.9$ & $88.1 \pm 16.8$ & $95.1 \pm 24.3$ & $101.3 \pm 24.2$ \\
\hline BMI & $17.9 \pm 2.0$ & $17.8 \pm 2.0$ & $22.3 \pm 3.6$ & $22.4 \pm 2.9^{*}$ \\
\hline BMI z-score & $0.04 \pm 0.80$ & $-0.05 \pm 0.80^{*}$ & $1.66 \pm 0.53$ & $1.45 \pm 0.47^{*}$ \\
\hline BSA & $1.13 \pm 0.13$ & $1.14 \pm 0.14^{*}$ & $1.41 \pm 0.29$ & $1.40 \pm 0.26$ \\
\hline WHtR & $0.42 \pm 0.13$ & $0.44 \pm 0.08$ & $0.51 \pm 0.12$ & $0.49 \pm 0.12$ \\
\hline Body fat (\%) & $22.50 \pm 6.31$ & $20.88 \pm 6.35^{*}$ & $32.38 \pm 6.21$ & $30.69 \pm 5.71^{*}$ \\
\hline
\end{tabular}

Values are presented as mean \pm standard deviation.

25(OH)D, 25 hydroxyvitamin D; PTH, parathyroid hormone; ALP, alkaline phosphatase; HDL-C, high-density lipoprotein cholesterol; LDL-C, low-density lipoprotein cholesterol; BMI, body mass index; BSA, body surface area; WHtR, waist to height ratio.

${ }^{*} P<0.05$. ${ }^{\dagger}$ Urine calcium/creatinine ratio.

Vitamin D Status in normal weight group (after vitamin D replacement)

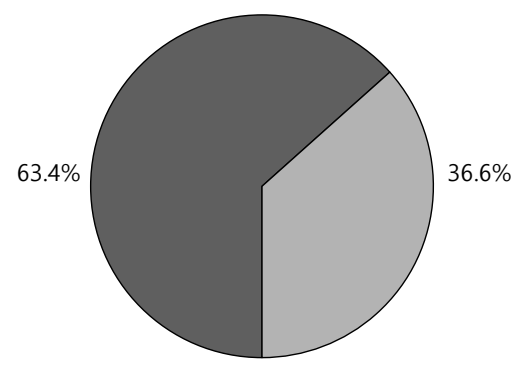

(A)

Sufficiency $\square$ Insufficiency
Vitamin D Status in overweight group (after vitamin D replacement)

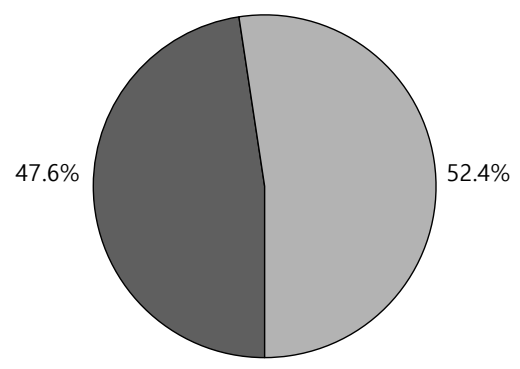

(B)

Sufficiency $\square$ Insufficiency

Fig. 1. Vitamin D Status in normal weight and overweight group after vitamin D replacement.

after vitamin D replacement, the serum 25(OH)D level increased from $14.2 \pm 2.1$ to $30.3 \pm 6.6 \mathrm{ng} / \mathrm{mL}(P<0.05)$.

The serum PTH level and urinary calcium/creatinine ratio did not change significantly in either group after vitamin D replacement (Table 2). The highest urinary calcium/creatinine ratio was 0.23 , which was detected in an 8.8 -year-old female patient in the normal-weight group without any symptoms.

After vitamin D replacement, all the participants in each group were free from VDD. However, in the normal-weight group, $63.4 \%$ achieved a sufficient level of $25(\mathrm{OH}) \mathrm{D}$, whereas only $47.6 \%$ of the overweight group achieved vitamin $\mathrm{D}$ sufficiency $\left(X^{2}=1.42, P=0.28\right)$ (Fig. 1A, B). After vitamin D replacement, the mean $\Delta 25(\mathrm{OH}) \mathrm{D}$ value was $20.8 \pm 7.1 \mathrm{ng} / \mathrm{mL}$ in the normal-weight group and $16.0 \pm 7.1 \mathrm{ng} / \mathrm{mL}$ in the overweight group $(P=0.02)$. The mean $\triangle \mathrm{PTH}$ values were $-0.45 \pm 18.88$ and $-9.02 \pm 23.75 \mathrm{pg} / \mathrm{mL}$ in the normal-weight and overweight
Table 3. $\Delta 25(\mathrm{OH}) \mathrm{D}$ and $\triangle \mathrm{PTH}$ after vitamin $\mathrm{D}$ replacement in normal weight and overweight groups

\begin{tabular}{lcc}
\hline Variable & Normal weight group & Overweight group \\
\hline$\triangle 25(\mathrm{OH}) \mathrm{D}(\mathrm{ng} / \mathrm{mL})$ & $20.8 \pm 7.1$ & $16.0 \pm 7.1^{*}$ \\
$\triangle \mathrm{PTH}(\mathrm{pg} / \mathrm{mL})$ & $-0.45 \pm 18.88$ & $-9.02 \pm 23.75$ \\
\hline Valus &
\end{tabular}

Values are presented as mean \pm standard deviation.

25(OH)D, 25 hydroxyvitamin D; PTH, parathyroid hormone. " $P<0.05$.

groups, respectively $(P=0.17)$ (Table 3 ).

A regression analysis was performed to determine the factors affecting the $\Delta 25(\mathrm{OH}) \mathrm{D}$ value. Sex, BMI, WHtR, body fat (\%), $\mathrm{WC}$, and BSA were identified as candidates affecting $\Delta 25(\mathrm{OH})$ D. In a univariate analysis after testing for collinearity, the model that included sex, BMI, WHtR, and body fat (\%) was selected. Sex $(P=0.046)$ and BMI $(P=0.035)$ were found to be the factors 
Table 4. Factors associated with $\Delta 25(\mathrm{OH}) \mathrm{D}$ in regression analysis

\begin{tabular}{lcc}
\hline & $\beta$ & $P$-value \\
\hline Sex & -4.00 & 0.04 \\
BMl & -0.93 & 0.03 \\
WHtR & -1.01 & 0.89 \\
Body fat (\%) & 0.16 & 0.42 \\
\hline 25(OH)D, 25 hydroxyvitamin D; BMl, body mass index; WHtR, \\
waist to height ratio.
\end{tabular}

affecting $\Delta 25(\mathrm{OH}) \mathrm{D}$ (Table 4).

\section{Discussion}

Vitamin D is a major component controlling calcium, phosphorus, and bone metabolism. Within the human body, vitamin $\mathrm{D}$ is hydroxylated in the liver to form $25(\mathrm{OH}) \mathrm{D}$, the major circulating form of vitamin D (with a half-life of 2 to 3 weeks), and then is further hydroxylated in the kidney to form $1 \alpha, 25$-dihydroxycholecalciferol $\left(1,25(\mathrm{OH})_{2} \mathrm{D}\right)$, the active form of vitamin D.") It is known that $1,25(\mathrm{OH})_{2} \mathrm{D}$ (with a half-life of four to six hours) has a high affinity for the vitamin $\mathrm{D}$ receptor (VDR), a member of the nuclear receptor superfamily. The VDR regulates the transcription of many target genes, and has been identified in osteoblasts, macrophages, smooth muscle, pancreatic $\beta$-cells, and adipose tissue in the human body. ${ }^{14-16)}$

VDD is a major health issue in the world, causing rickets in young children and osteomalacia in adults. ${ }^{2)}$ According to recent studies, VDD is related to obesity level, BMI, WC, and visceral fat amount, but the underlying mechanism is uncertain. ${ }^{17,18)}$ Growing evidence suggests that adipose tissue could be a target organ of vitamin $\mathrm{D},{ }^{19,20)}$ and the VDR was recently found in human adipose tissue. ${ }^{16)}$ In a study for women undergoing gynecological surgery, calcium and vitamin D intake reduced the size of adipocytes, ${ }^{21)}$ and in another study for overweight and obese adults, calcium and vitamin D supplementation reduced the amount of visceral abdominal adipose tissue. ${ }^{22)}$

According to the Endocrine Society treatment guidelines for children 1-18 years old who are vitamin D deficient, the recommended dose of vitamin D supplementation is 2,000 IU/ day for at least 6 weeks, ${ }^{7)}$ and in the case of nutritional rickets, the recommended dose is 2,000 IU/day for a minimum of 3 months. ${ }^{23)}$ Following these vitamin D deficiency treatment guidelines, we designed our study to include vitamin $\mathrm{D}$ supplementation (2,000 IU/day) for 8 weeks. After this vitamin D replacement, our patients were advised to receive 600 to 1,000 $\mathrm{IU} /$ day (the daily requirement of vitamin D) ${ }^{7,23)}$

In this study, after vitamin D replacement, the BMI, BMI $z$-score and body fat (\%) values improved in both groups. However, it is unclear whether the improvements in BMI and body fat (\%) resulted from the vitamin D replacement or from changes in the patients' lifestyles due to enrollment in the study itself.

After vitamin D replacement, the increment of $25(\mathrm{OH}) \mathrm{D}$ was higher in the normal-weight group than in the overweight group. It is known that overweight individuals generally have a higher requirement for vitamin $\mathrm{D}$ due to the lipid-soluble nature of this vitamin. ${ }^{2)}$ Based on recent clinical and experimental studies, it is also conceivable that adipose tissue is a target organ of vitamin $\mathrm{D} .{ }^{16)}$ Thus, in obese individuals, the lipid-soluble nature of vitamin $\mathrm{D}$ and the higher number of adipocytes that consume vitamin D may work together to reduce the serum $25(\mathrm{OH}) \mathrm{D}$ level, such that a higher dose of vitamin $\mathrm{D}$ is required to increase the serum $25(\mathrm{OH}) \mathrm{D}$ level.

In the Endocrine Society treatment guidelines for VDD, a 2- or 3 times higher dose of vitamin D supplementation is recommended for obese patients than for normal-weight individuals due to the reduced bioavailability of vitamin $\mathrm{D}^{7.24)}$ However, evidence to set the treatment dose for VDD in obese children is lacking, and the guidelines focus on the upper limit of 25(OH)D without toxicity. ${ }^{7)}$ According to our study, a higher dose of vitamin D may be required to attain vitamin D sufficiency in overweight children than in normal-weight children; however, 8 weeks of vitamin D replacement (2,000 IU/ day) was sufficient to overcome VDD in both normal-weight and overweight children. Also, after vitamin D replacement, the vitamin $\mathrm{D}$ status distribution did not differ between the two groups $\left(X^{2}=1.42, P=0.28\right)$.

Another concern is that the effects of an insufficient vitamin D status on growing children are unknown, and the proper levels of vitamin $\mathrm{D}$ throughout the life cycle are still being debated. ${ }^{25,26)}$

The limitations of our study included the short span of observation and the small number of participants. Thus, the statistical results were not sufficient to explain the changes in BMI and body fat (\%). Also, in the overweight group, the BMI values were not particularly high, which could have diluted the difference in response to vitamin $\mathrm{D}$ replacement between the groups.

In conclusion, 8 weeks of vitamin $\mathrm{D}$ replacement (2,000 IU/ day) was sufficient to overcome vitamin D deficiency in normalweight and overweight children without any complications. Additionally, after vitamin D replacement, the BMI, BMI $z$-score, and body fat (\%) values improved. Further research is required to reveal the effects of vitamin D replacement on adipocytes in children.

\section{Ethical statement}

This study was approved by the CHA Bundang Medical Center Institutional Review Board (approval number: BD 2013126). Informed consent was obtained from each participant and their parents.

\section{Conflict of interest}

No potential conflict of interest relevant to this article was reported. 


\section{Acknowledgment}

This study was supported by FND Net Co., Ltd.

\section{References}

1. DeLuca HF. Overview of general physiologic features and functions of vitamin D. Am J Clin Nutr 2004;80(6 Suppl):1689S-1696S.

2. Holick MF. Vitamin D deficiency. N Engl J Med 2007;357:266-81

3. Cheng S, Massaro JM, Fox CS, Larson MG, Keyes MJ, McCabe EL, et al. Adiposity, cardiometabolic risk, and vitamin D status: the Framingham Heart Study. Diabetes 2010;59:242-8.

4. Jorde R, Sneve M, Emaus N, Figenschau Y, Grimnes G. Cross-sectional and longitudinal relation between serum 25-hydroxyvitamin D and body mass index: the Tromsø study. Eur J Nutr 2010;49:401-7.

5. Rajakumar K, de las Heras J, Chen TC, Lee S, Holick MF, Arslanian SA. Vitamin D status, adiposity, and lipids in black American and Caucasian children. J Clin Endocrinol Metab 2011;96:1560-7.

6. Chung IH, Kim HJ, Chung S, Yoo EG. Vitamin D deficiency in Korean children: prevalence, risk factors, and the relationship with parathyroid hormone levels. Ann Pediatr Endocrinol Metab 2014;19:86-90.

7. Holick MF, Binkley NC, Bischoff-Ferrari HA, Gordon CM, Hanley DA, Heaney RP, et al. Evaluation, treatment, and prevention of vitamin D deficiency: an Endocrine Society clinical practice guideline. J Clin Endocrinol Metab 2011;96:1911-30.

8. Zittermann A, Ernst JB, Gummert JF, Börgermann J. Vitamin D supplementation, body weight and human serum 25-hydroxyvitamin D response: a systematic review. Eur J Nutr 2014;53:367-74.

9. Obesity: preventing and managing the global epidemic. Report of a WHO consultation. World Health Organ Tech Rep Ser 2000;894:1-253.

10. Huh SY, Gordon CM. Vitamin D deficiency in children and adolescents: epidemiology, impact and treatment. Rev Endocr Metab Disord 2008;9:161-70.

11. Johnson ST, Kuk JL, Mackenzie KA, Huang TT, Rosychuk RJ, Ball GD. Metabolic risk varies according to waist circumference measurement site in overweight boys and girls. J Pediatr 2010;156:247-52.

12. Cole TJ, Bellizzi MC, Flegal KM, Dietz WH. Establishing a standard definition for child overweight and obesity worldwide: international survey. BMJ 2000;320:1240-3.
13. Mosteller RD. Simplified calculation of body-surface area. N Engl J Med 1987;317:1098.

14. Norman AW. Minireview: vitamin D receptor: new assignments for an already busy receptor. Endocrinology 2006;147:5542-8.

15. Plum LA, DeLuca HF. Vitamin D, disease and therapeutic opportunities. Nat Rev Drug Discov 2010;9:941-55.

16. Ding C, Gao D, Wilding J, Trayhurn P, Bing C. Vitamin D signalling in adipose tissue. Br J Nutr 2012;108:1915-23.

17. Snijder MB, van Dam RM, Visser M, Deeg DJ, Dekker JM, Bouter LM, et al. Adiposity in relation to vitamin D status and parathyroid hormone levels: a population-based study in older men and women. J Clin Endocrinol Metab 2005;90:4119-23.

18. Parikh SJ, Edelman M, Uwaifo GI, Freedman RJ, Semega-Janneh M, Reynolds J, et al. The relationship between obesity and serum 1,25-dihydroxy vitamin D concentrations in healthy adults. J Clin Endocrinol Metab 2004;89:1196-9.

19. Wong KE, Kong J, Zhang W, Szeto FL, Ye H, Deb DK, et al. Targeted expression of human vitamin $\mathrm{D}$ receptor in adipocytes decreases energy expenditure and induces obesity in mice. J Biol Chem 2011;286:33804-10.

20. Ching S, Kashinkunti S, Niehaus MD, Zinser GM. Mammary adipocytes bioactivate 25 -hydroxyvitamin $\mathrm{D}_{3}$ and signal via vitamin $\mathrm{D}_{3}$ receptor, modulating mammary epithelial cell growth. J Cell Biochem 2011;112:3393-405.

21. Caron-Jobin M, Morisset AS, Tremblay A, Huot C, Légaré D, Tchernof A. Elevated serum 25(OH)D concentrations, vitamin $\mathrm{D}$, and calcium intakes are associated with reduced adipocyte size in women. Obesity (Silver Spring) 2011;19:1335-41.

22. Rosenblum JL, Castro VM, Moore CE, Kaplan LM. Calcium and vitamin D supplementation is associated with decreased abdominal visceral adipose tissue in overweight and obese adults. Am J Clin Nutr 2012;95:101-8.

23. Munns CF, Shaw N, Kiely M, Specker BL, Thacher TD, Ozono K, et al. Global consensus recommendations on prevention and management of nutritional rickets. J Clin Endocrinol Metab 2016;101:394-415.

24. Wortsman J, Matsuoka LY, Chen TC, Lu Z, Holick MF. Decreased bioavailability of vitamin D in obesity. Am J Clin Nutr 2000;72:690-3.

25. Rosen CJ. Clinical practice. Vitamin D insufficiency. N Engl J Med 2011;364:248-54.

26. Rosen CJ, Abrams SA, Aloia JF, Brannon PM, Clinton SK, Durazo-Arvizu RA, et al. IOM committee members respond to Endocrine Society vitamin D guideline. J Clin Endocrinol Metab 2012;97:1146-52. 